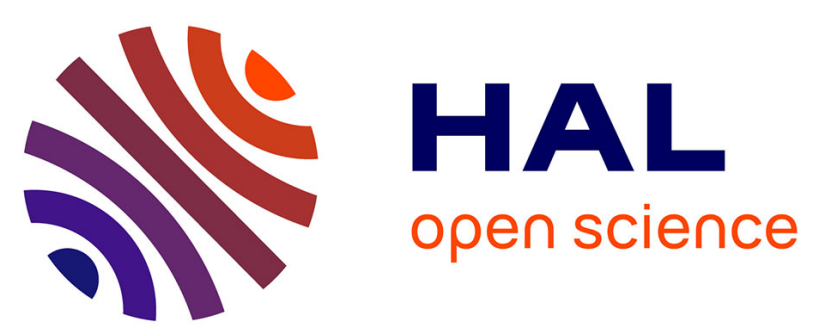

\title{
AN UNDERSTANDING OF IN SITU BORON DOPED POLYSILICON FILMS BY CHARACTERIZATION AND SIMULATION
}

\author{
C. Azzaro, E. Scheid, D. Bielle-Daspet, P. Duverneuil, P. Boudre
}

\section{To cite this version:}

C. Azzaro, E. Scheid, D. Bielle-Daspet, P. Duverneuil, P. Boudre. AN UNDERSTANDING OF IN SITU BORON DOPED POLYSILICON FILMS BY CHARACTERIZATION AND SIMULATION. Journal de Physique IV Proceedings, 1991, 02 (C2), pp.C2-79-C2-85. 10.1051/jp4:1991209 . jpa00249776

\section{HAL Id: jpa-00249776 https://hal.science/jpa-00249776}

Submitted on 1 Jan 1991

HAL is a multi-disciplinary open access archive for the deposit and dissemination of scientific research documents, whether they are published or not. The documents may come from teaching and research institutions in France or abroad, or from public or private research centers.
L'archive ouverte pluridisciplinaire HAL, est destinée au dépôt et à la diffusion de documents scientifiques de niveau recherche, publiés ou non, émanant des établissements d'enseignement et de recherche français ou étrangers, des laboratoires publics ou privés. 
Collogue C2, suppl. au Journal de Physique II, Vol 1, septembre 1991

\title{
AN UNDERSTANDING OF IN SITU BORON DOPED POLYSILICON FILMS BY CHARACTERIZATION AND SIMULATION
}

\author{
C. AZZARO, E. SCHEID* , D. BIELLE-DASPET* , P. DUVERNEUIL and \\ P. BOUDRE* \\ LGC URA, 192 du CNRS-ENSIGC, Chemin de la Loge, F-31078 Toulous \\ cedex, France \\ " LAAS du CNRS, 7, av. du Colonel Roche, F-31077 Toulouse \\ cedex, France \\ * MOTOROTi, av. du Général Eisenhower, F-31023 Toulouse cedex, \\ France
}

\begin{abstract}
A new understanding of the deposition of in situ boron doped polysilicon based on a comparison between experimental results and modeling predictions, is proposed. The depletion of both silane and boron trichloride is put in evidence and the necessity of the use of injectors is established.
\end{abstract}

\section{1 - Introduction}

The in situ doping of polysilicon is of interest $/ 1 /$, as this technique makes it possible to reduce, both the number of steps involved in the preparation of the doped layer and the amount of equipments required to process the wafers. For boron doped polysilicon, two ways in industry have been considered: (1)-from diborane $/ 2 / \mathrm{B}_{2} \mathrm{H}_{6}$, but covered boats are required to obtain a good uniformity across a wafer, (2)- from boron trichloride $/ 1 / \mathrm{BCl}_{3}$, but the use of injectors is required.

In this work, studies are devoted to the $\mathrm{SiH}_{4}-\mathrm{BCl}_{3}$ system $/ 1$, where normally the design of injectors is empirical and consequently seldom satisfactory because the use of such a system requires significant maintenance, due to the filling-in of the holes.

In this paper, a studied approach of the in situ boron doped polysilicon is carried out, taking into account, on the one hand, experimental and simulation results of the deposition step and, on the other hand, electronic and physical characterizations. Comparison is made between results obtained with or without the use of injectors, in order to achieve a better understanding of the physical and chemical phenomena underlying the deposition.

\section{2 - Experimental results}

Deposition is made in a horizontal LPCVD reactor in isothermal conditions at $555^{\circ} \mathrm{C}$ from $\mathrm{SiH}_{4}(200 \mathrm{sccm})$ and $\mathrm{BCl}_{3}$ diluted at $3 \%$ in $\mathrm{N}_{2}(90 \mathrm{sccm})$, injected from the front door, at a pressure of $46.7 \mathrm{~Pa}$, without injectors and compared with results obtained when $40 \mathrm{sccm}$ of the $\mathrm{BCl}_{3}+\mathrm{N}_{2}$ are spread by the injectors, and $50 \mathrm{sccm}$ injected from the front door $/ 1 /$. The load included in both cases 162 wafers of $5^{\prime \prime}$ silicon wafers, separated by a $3.8 \mathrm{~mm}$ interval. The position of each of the wafers in the batch is indicated by a number starting from 1 (first wafer reached by the gases) to 162 (last wafer reached).

For every wafer, the thickness of the deposit layer has been measured by an interferometrics method and the silicon growth rate has been deduced from it. The boron concentration has been evaluated by SIMS experiments and conductivity measurements have also been made. 


\section{1- Results without injectors}

Figure 1 shows that the deposition rate varies linearly with the position, from 85 to $32 \AA / \mathrm{min}$.

SIMS experiments (see Table 1) indicate a boron concentration of $1.310^{21} \mathrm{~cm}^{-3}$ on the wafer $\mathrm{n}^{\circ} 82$, and 5 times lower on the wafer 136 . Conductivity measurements are given in figure 2 , which shows that a maximum value of $510 \mathrm{s.cm}^{-1}$ is obtained between position 10 and 50 , and that a minimum value of $120 \mathrm{s.cm}^{-1}$ is obtained on the last wafers of the load. The two mass balances on silane and on boron trichloride, taking into account respectively the silicon and the boron atoms deposited on the solid surfaces, put in evidence conversion rates of $30 \%$ and $80 \%$.

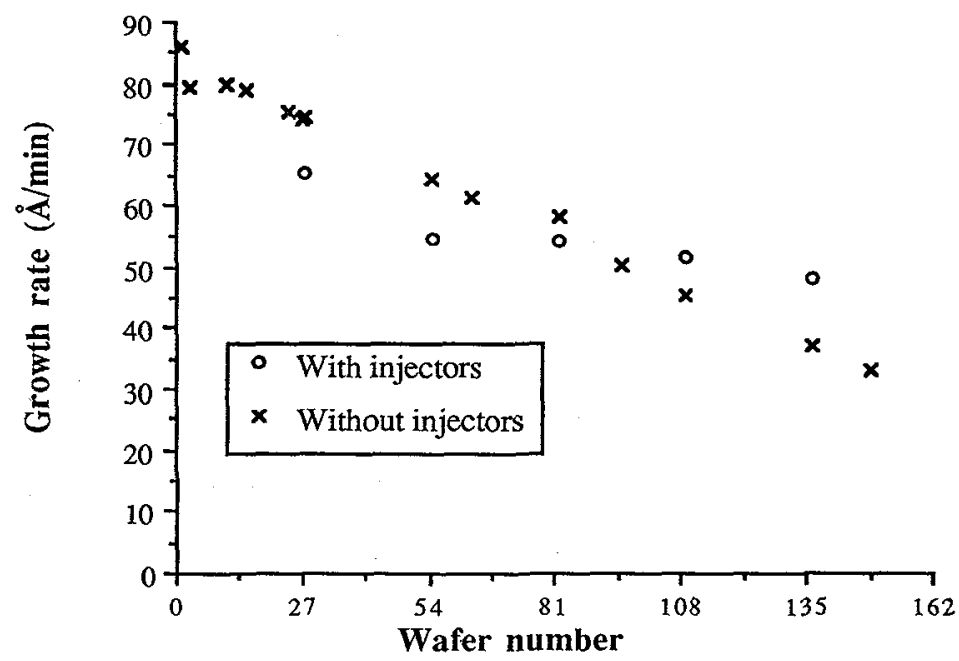

Fig. 1: Experimental polysilicon growth rate along the reactor with and without injectors

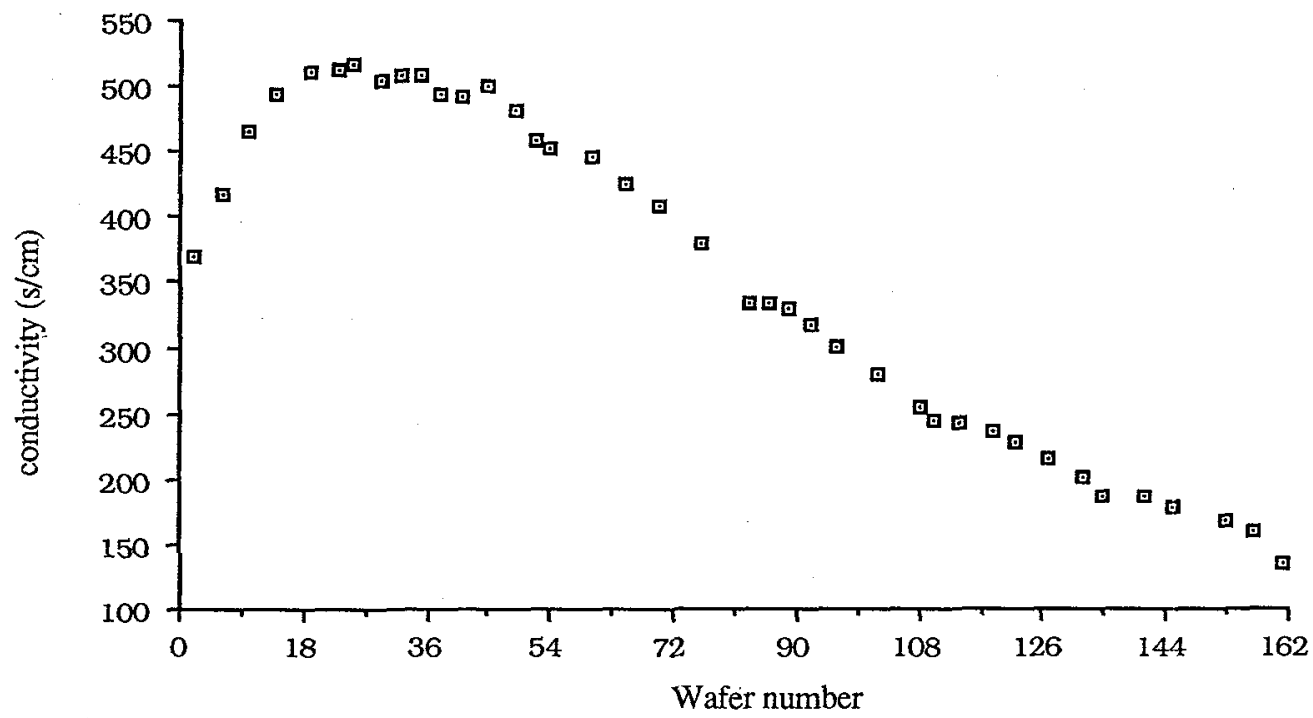

Fig. 2: Conductivity measurements 
Table 1: SIMS measurements (without and with injectors)

\begin{tabular}{|c|c|c|}
\hline & Wafer number & $\mathrm{C}_{\mathrm{B}}\left(\mathrm{At} / \mathrm{cm}^{3}\right)$ \\
\hline Without injectors & 1 & $2.210^{21}$ \\
\hline Without injectors & 82 & $1.310^{21}$ \\
\hline Without injectors & 136 & $410^{20}$ \\
\hline With injectors & 28 & $2.510^{21}$ \\
\hline With injectors & 135 & $1.510^{21}$ \\
\hline
\end{tabular}

\section{2- Results with injectors}

The values of deposition rate (Fig. 1), boron concentration and conductivity obtained in presence of injectors are approximatively the same on the wafer $n^{\circ} 82$ (middle of the load) as without injectors. It has been observed that the gradient of variation of all these properties along the load is much lower in presence of injectors.

\section{3- Comparison with the deposition from diborane $/ 2 /$}

At the same pressure and at $\mathrm{T}=560^{\circ} \mathrm{C}$, the silicon growth rate obtained from the $\mathrm{SiH}_{4}-\mathrm{B}_{2} \mathrm{H}_{6}$ gas mixture is lower, i.e. $40 \AA / \mathrm{min}$, than the growth rate obtained from the $\mathrm{SiH}_{4}-\mathrm{BCl}_{3}$ mixture, for the same value of the boron source / silane flow ratio. The mean conductivity is also lower in the former case, i.e. $170 \mathrm{~s} / \mathrm{cm}$. Finally, the boron doped silicon films on a wafer are more uniform from a $\mathrm{SiH}_{4}-\mathrm{BCl}_{3}$ mixture.

\section{3 - Simulation results}

The deposition of in situ boron doped polysilicon has been treated via a global modeling approach $3,4 /$. The unidirectional model has been elaborated, taking only into account the reactions on solid surfaces:

$$
\begin{aligned}
& \text { Silicon deposition } / 5 /: \mathrm{SiH}_{4} \rightarrow \mathrm{Si}+2 \mathrm{H}_{2} \\
& \text { Boron deposition : } \mathrm{BCl}_{3} \rightarrow \mathrm{B}+3 / 2 \mathrm{Cl}_{2}
\end{aligned}
$$

In this simple model $/ 3,4 /$, the gas phase chemistry is neglected, not only the silane decomposition but also the possible formation of boron-silicon compounds.

The expression (1) for the pure silicon deposition has been deduced from /5/:

$$
V_{\text {Pure Si poly }}=\frac{k P_{S_{i H}}}{1+k_{h} P_{\mathrm{H}_{2}}+k_{\mathrm{S}} \mathrm{P}_{\mathrm{SiH}_{4}}}
$$

The terms $k, k_{h}$ et $k_{s}$ are constants representative of gas adsorption at the surface and decomposition of the gases in the reactor volume.

The enhancement factor of silicon deposition, in the presence of boron atoms in the gas phase, has been taken as a function of the ratio of the concentrations in the gas phase of silane and boron trichloride. Finally, the silicon growth rate (2) has been expressed as follows:

$$
V_{\text {Boron doped Si poly }}=\left(1+a \frac{\mathrm{X}_{\mathrm{SiH}_{4}}}{\mathrm{X}_{\mathrm{BCl}_{3}}}\right) \mathrm{V}_{\text {Pure Si poly }}
$$

The constant a has been adjusted by successive simulations in order to fit with the experimental data of the growth rate. 
The kinetics of boron deposition (3) has been deduced from the incorporation rate $\mathrm{C}_{B}$ of the boron into the silicon:

$$
\mathrm{V}_{\text {Boron }}=\left(\frac{\mathrm{C}_{\mathrm{B}} \cdot \mathrm{M}_{\mathrm{Si}}}{\rho_{\mathrm{Si}} \cdot \mathfrak{N}}\right) \mathrm{V}_{\text {Boron doped } \mathrm{Si}}
$$

$\mathrm{M}_{\mathrm{Si}}, \rho_{\mathrm{Si}}$ and $\mathcal{N}$ represent respectively the molar mass of silicon, the density of silicon and the Avogadro number. The incorporation rate of boron into the silicon has been adjusted, so that the values of the growth rate predicted by the model fit the experimental data.

\section{4 - Comparison between experimental results and modeling predictions}

\section{1- Comparison without injectors}

The comparison between experimental and simulation results is displayed in Fig. 3. for the run implemented without injectors.

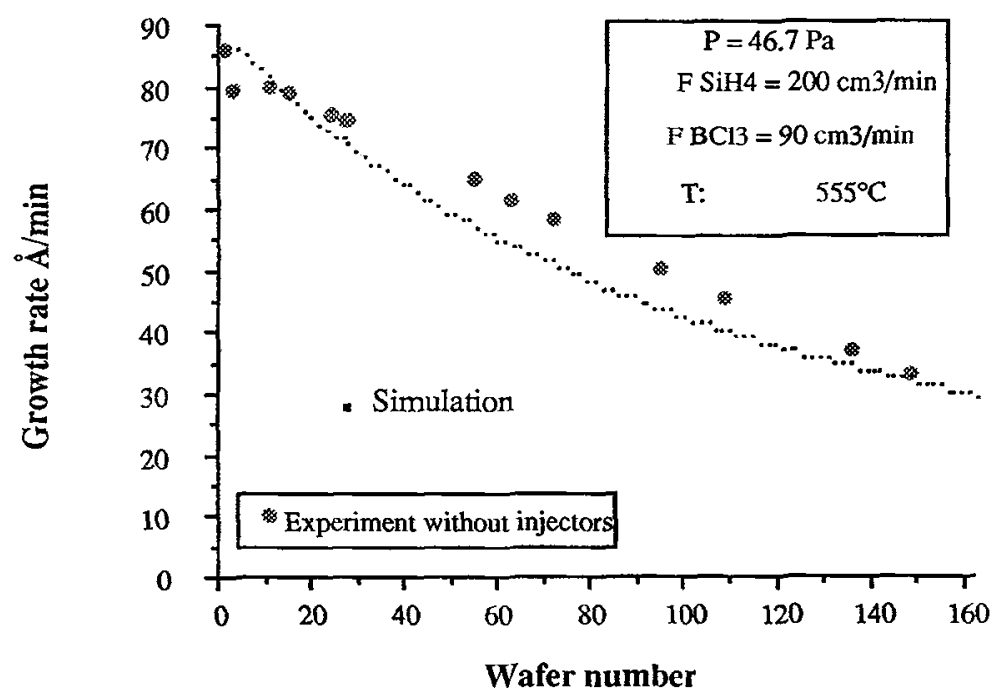

Fig. 3: Comparison between experimental and simulation results (without injectors)

The calculated profile of the boron incorporation rate into the silicon layer along the reactor is presented in Fig. 4. The order of magnitude of $C_{B}$ is comparable to the experimental results given by SIMS and relative to the wafer $n^{\circ} 82$. 
Boron Concentration

$\mathrm{At} / \mathrm{cm}^{3}(\mathrm{x} \quad 10-21)$

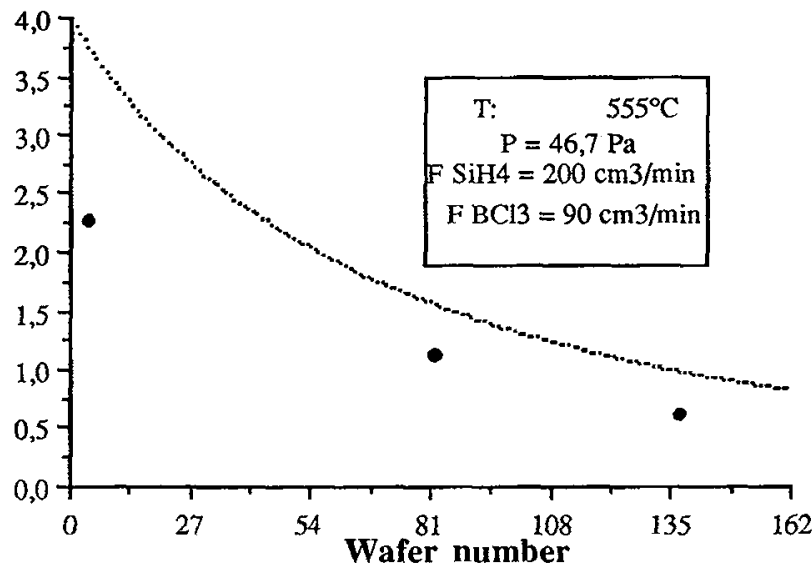

-- Calculated profile

- Experimental profile

Fig. 4: Calculated and experimental profiles of the boron concentration

It can be seen that the model represents satisfactorily the severe depletions of silane (see fig. 3) and boron trichloride (see fig. 4) observed experimentally.

\section{2- Comparison with injectors}

The profile corresponding to the presence of injectors has been evaluated by sinulation: the results are presented in Fig. 5 and are in agreement with the experimental data, also indicated in the same figure.

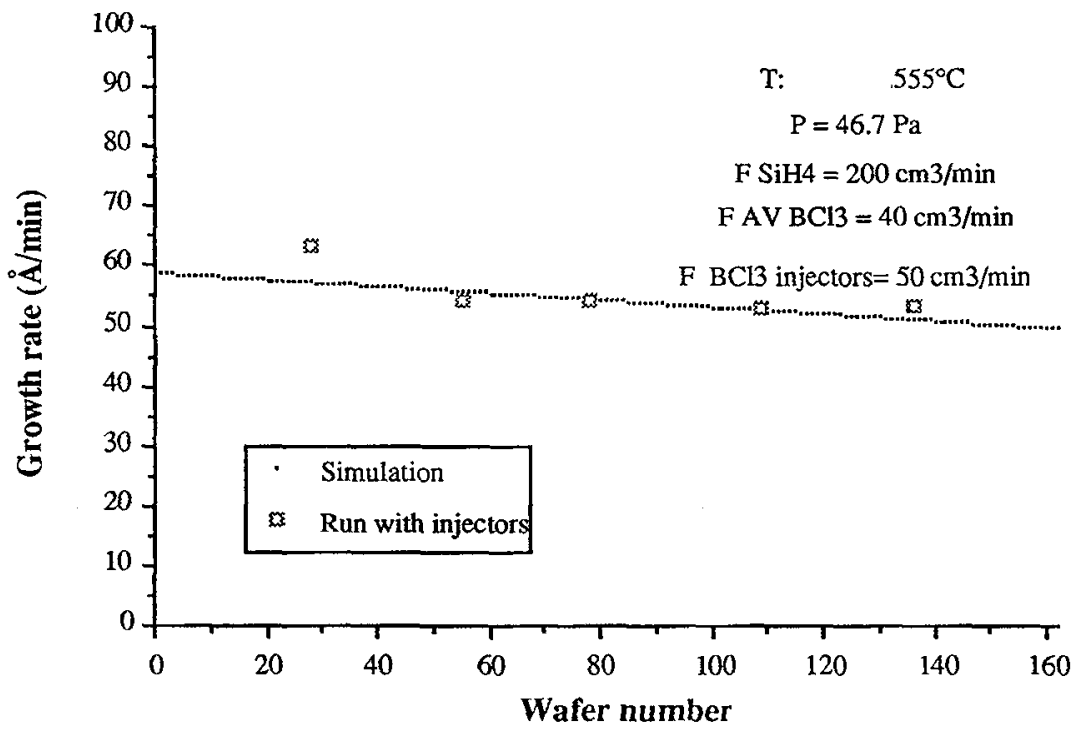

Fig. 5: Comparison between experimental and simulation results (with injectors) 


\section{5 - Characterization of the crystalline quality of the films obtained without injectors.}

It must be noted in figure 2 that conductivity increases between wafers 1 and 10 , whereas we established experimentally that boron concentration decreases. This effect is certainly due to a lower temperature profile on the first wafers $13 /$. It can also be shown that the conductivity decreases less quickly than the boron concentration between wafers 82 and 136. These apparent discrepancies were already noticed in a previous work $/ 1 /$, where we saw that the conductivity of B-doped Si films decreases when the temperature of deposition increases.

We showed that this was related to the crystalline quality of the deposit, which was crystallized at a deposition temperature higher than $520^{\circ} \mathrm{C}$; it has also been observed that the higher the temperature is, the smaller the grain size is.

A correlation was also established between the grain size given by Raman experiments (i.e. the size of grain without defects) and optical constants $\mathrm{n}$ and $\mathrm{k}$ at $405 \mathrm{~nm}$. We thus demonstrated that, as the crystalline quality of a polycrystalline layer increases, $\mathrm{n}$ and $\mathrm{k}$ move from the values of amorphous silicon $(n=4.8 ; k=2.2)$ to the values of crystalline silicon $(n=5.42 ; k=0.329)$, i.e $n$ increases and $k$ decreases: Figure 6 shows the values of these parameters across the load.

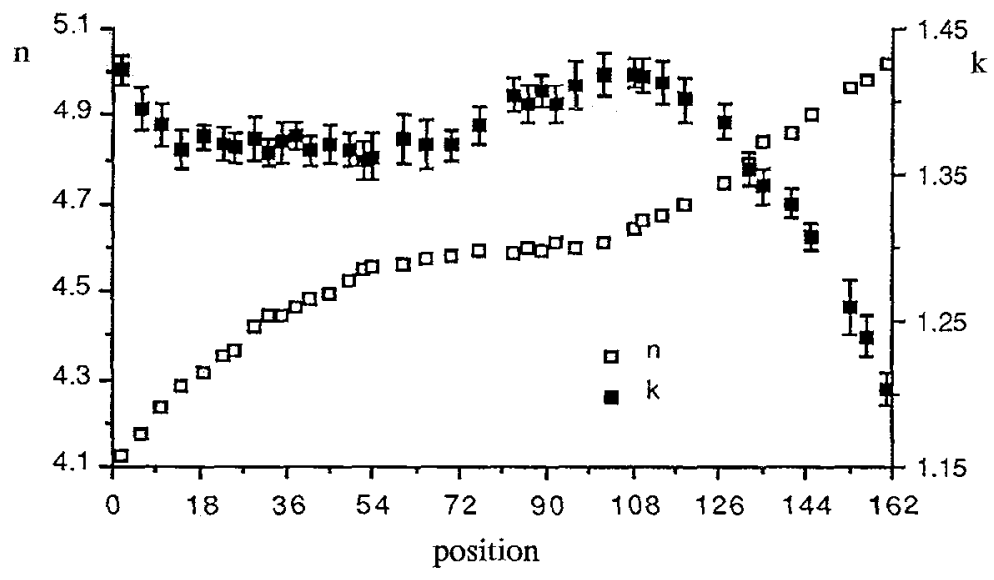

Fig. 6: Evolution of the optical constants $\mathrm{n}$ and $\mathrm{k}$ at $405 \mathrm{~nm}$ along the load

It can be noticed that $\mathrm{n}$ increases monotonically across the load, and that $\mathrm{k}$ decreases between wafer 1 and 10 and then is almost stable until wafer 125 . We then deduce that the evolution of conductivity across the load results from the balance between the boron concentration which decreases and the mobility which increases with the crystallinity. In particular, the crystalline quality on the first wafers is so bad that the conductivity is lower than on wafers 10 to 50 . This evolution of crystallinity is due to the evolution of the nucleation rate which is a priori proportional to boron atoms concentration, and to the evolution of the deposition rate. As the product nucleation rate by deposition rate decreases, the grain size or the defect density decreases, leading to a higher crystalline quality. As TEM in plan-view does not indicate any clear evolution of apparent grain size, the evolution of mobilty must rather be due to an evolution in defect density inside the grains. We believe that this explanation fits well the behaviour of the conductivity and of the optical constants across the load. 


\section{6 - Comments and conclusion}

In this work, the strong exhaustion of boron trichloride during in situ boron doped polysilicon deposition under industrial conditions has been shown.

First, a convenient identification of kinetic parameters has allowed us to develop a model fitting the experimental data. This model constitutes a useful tool for choosing appropriate operating conditions, for giving longitudinal variations in silicon growth rate in agreement with strict industrial specifications.

Second, some elements brought out in this study make possible the choice of the quality of the deposited layers, according to their applications; for instance, this work suggests that films of conductivity superior to the values reported in this article can be achieved, which is of interest for the fabrication of connection layers.

\section{Acknowledgements:}

We are indebted to $\mathbb{C}$. Armand (LAAS CNRS Toulouse) and J.P. Dupuy (LPS-INSA Lyon) for the SIMS measurements.

This work was partly supported by the french Ministère de la Recherche et de la Technologie .

\section{References:}

/1/ BIELLE-DASPET D., SCHEID E., AZZARO C., DE MAUDUIT B. , PIERAGGI B. : to be published in Thin Solid Films (1991).

12/ MARITAN C.M., BERNDT L.P. , TARR N.G., BULLERWELL J.M., JENKINS G.M.: J. Electrochem. Soc., 135, (1988), 1793 .

13/ AZZARO C. , DUVERNEUIL P., COUDERC J.P., Modeling of pure and in situ doped polycrystalline silicon deposition in LPCVD reactors, to be published in Materials and Manufacturing Processes.

14/ AZZARO C. ,Thèse de Doctorat INPT (21 Février 1991), Analyse et Modélisation du fonctionnement des réacteurs de dépôt chimique en phase vapeur: Cas du silicium pur et dopé in situ 15/ JENSEN K.F., GRAVES D.B., J. Electrochem. Soc., 139, (1983), 1951 . 